\title{
Severe, Persistent, Painful Neuropathy Relieved Immediately After Surgical Release: Case of Neurostenalgia of the Radial Nerve
}

\author{
Jung-Gyoo Park, MD ${ }^{1}$, Hannae Jo, MD ${ }^{1}$, Hee-won Park, MD, MA ${ }^{1,2}$, Sora Baek, MD, PhD ${ }^{1,3}$ \\ ${ }^{1}$ Department of Rehabilitation Medicine, Kangwon National University Hospital, Chuncheon; \\ ${ }^{2}$ Gangwon-do Rehabilitation Hospital, Chuncheon; ${ }^{3}$ Department of Rehabilitation Medicine, \\ Kangwon National University School of Medicine, Chuncheon, Korea
}

Neurostenalgia is a neuropathic pain that results from continuing irritation of an anatomically intact nerve by a noxious agent. The pain resolves promptly after surgical release of the nerve. The authors report a case of neurostenalgia of the radial nerve in which the posterior interosseous branch was compressed at the arcade of Frohse, presenting with severe arm and elbow pain. The pain was immediately relieved after surgical release of the nerve.

Keywords Neurostenalgia, Radial nerve, Posterior interosseous nerve

\section{INTRODUCTION}

Neurostenalgia is a neuropathic pain that results from continuing mechanical irritation of an anatomically intact nerve which is promptly resolved after surgical release of the nerve. Entrapment of the posterior interosseous nerve (PIN) is characterized by weakness only or weakness accompanied by mild pain [1]. Extreme pain with weakness of the wrist and finger might be falsely diagnosed as neuralgic amyotrophy or musculoskeletal

Received June 3, 2014; Accepted August 22, 2014

Corresponding author: Sora Baek

Department of Rehabilitation Medicine, Kangwon National University Hospital, 156 Baengnyeong-ro, Chuncheon 200-722, Korea

Tel: +82-33-258-9262, Fax: +82-33-258-9097, E-mail: sora.baek@kangwon. ac.kr

(c) This is an open-access article distributed under the terms of the Creative Commons Attribution Non-Commercial License (http://creativecommons. org/licenses/by-nc/3.0) which permits unrestricted noncommercial use, distribution, and reproduction in any medium, provided the original work is properly cited.

Copyright (C) 2015 by Korean Academy of Rehabilitation Medicine disorder. The authors report a case presenting with severe arm and elbow pain due to neurostenalgia of radial nerve.

\section{CASE REPORT}

A 22-year-old female had a sudden onset of severe pain from the left distal arm to the dorsal side of the left forearm and hand, accompanied by weakness of the wrist and finger extensors. After conservative management under the suspicion of musculoskeletal or cervical disorders, the pain was not relieved. Three weeks after the onset of pain, she was referred to our department for an electrophysiologic study (electromyography [EMG]/ nerve conduction study [NCS]). She kept her elbow in flexion and forearm in pronation; any attempt to neutralize elbow flexion and forearm pronation provoked severe pain. There was severe tenderness over the lateral elbow and arm; Tinel sign at the elbow was strongly positive. In 
Table 1. Motor power and findings of the NCS and needle electromyography in pre- and post-operative evaluations

\begin{tabular}{|c|c|c|c|c|}
\hline & Pre-OP & Post-OP (2 mo) & Post-OP (6 mo) & Post-OP (9 mo) \\
\hline \multicolumn{5}{|l|}{ Motor power ${ }^{a)}$} \\
\hline Lt. ECU & 0 & 0 & 1 & 2 \\
\hline Lt. EDC & 0 & 0 & 1 & 2 \\
\hline \multicolumn{5}{|l|}{ Motor NCS } \\
\hline Lt. radial nerve & No response & No response & No response & No response \\
\hline \multicolumn{5}{|l|}{ Sensory NCS } \\
\hline Lt. superficial radial nerve & $40 \mu \mathrm{V}$ ( $46 \%$ of Rt.) & $18 \mu \mathrm{V}(36 \%$ of Rt.) & $36 \mu \mathrm{V}(44 \%$ of Rt. $)$ & $43.8 \mu \mathrm{V}$ (37\% of Rt.) \\
\hline \multicolumn{5}{|l|}{ Needle electromyography } \\
\hline Lt. brachioradialis & $\begin{array}{l}\text { Fibs \& PSWs (1+); } \\
\text { Normal MUAP }\end{array}$ & $\begin{array}{l}\text { Fibs \& PSWs (1+); } \\
\text { Normal MUAP }\end{array}$ & WNL & WNL \\
\hline Lt. ECRL & $\begin{array}{l}\text { Fibs \& PSWs (1+); } \\
\text { Normal MUAP }\end{array}$ & WNL & WNL & WNL \\
\hline Lt. supinator ${ }^{b)}$ & Fibs \& PSWs $(1+)$ & NT & NT & NT \\
\hline Lt. EDC & $\begin{array}{l}\text { Fibs \& PSWs }(1+) ; \\
\text { No MUAP }\end{array}$ & $\begin{array}{l}\text { Fibs \& PSWs }(2+) \\
\text { No MUAP }\end{array}$ & $\begin{array}{l}\text { Fibs \& PSWs }(2+) ; \\
\text { Polyphasic MUAP } \\
\text { c single R }\end{array}$ & NT \\
\hline Lt. ECU & $\begin{array}{l}\text { Fibs \& PSWs }(1+) ; \\
\text { No MUAP }\end{array}$ & $\begin{array}{l}\text { Fibs \& PSWs }(2+) ; \\
\text { No MUAP }\end{array}$ & $\begin{array}{l}\text { Fibs \& PSWs }(2+) ; \\
\text { Polyphasic MUAP } \\
\text { c single R }\end{array}$ & $\begin{array}{l}\text { Fibs \& PSWs }(1+) ; \\
\text { Polyphasic MUAP } \\
\text { c reduced R }\end{array}$ \\
\hline Lt. EIP & $\begin{array}{l}\text { Fibs \& PSWs }(1+) \\
\text { No MUAP }\end{array}$ & $\begin{array}{l}\text { Fibs \& PSWs }(2+) \\
\text { No MUAP }\end{array}$ & $\begin{array}{l}\text { Fibs \& PSWs }(3+) ; \\
\text { Polyphasic MUAP } \\
\text { c single R }\end{array}$ & $\begin{array}{l}\text { Fibs \& PSWs }(1+) ; \\
\text { Polyphasic MUAP } \\
\text { c reduced R }\end{array}$ \\
\hline
\end{tabular}

NCS, nerve conduction study; Rt, right; Lt, left; OP, operation; ECU, extensor carpi ulnaris; EDC, extensor digitorum communis; ECRL, extensor carpi radialis longus; EIP, extensor indicis proprius; Fib, fibrillation potential; PSW, positive sharp wave; MUAP, motor unit action potential; WNL, within normal limit; c, with; NT, not tested; R, recruitment.

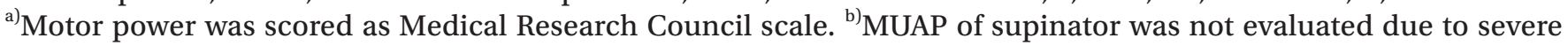
pain in pre-operative electromyography.

muscle strength test, the left finger and thumb extensors, and the extensor carpi ulnaris (ECU) showed no muscle contraction (Table 1). Her wrist was radially deviated during active dorsiflexion; motor power of the left brachioradialis and extensor carpi radialis (ECR) strength was normal. There was no hypesthesia in her left upper extremity.

EMG/NCS results suggested a severe PIN neuropathy and moderate injury to the superficial radial nerve (SRN). Radial motor nerve conduction study recorded in the extensor indicis proprius (EIP) was not elicited. SRN nerve conduction study was elicited, but the amplitude was significantly reduced ( $40 \mu \mathrm{V}$ in left, $87 \mu \mathrm{V}$ in right). Motor unit action potential (MUAP) was not recruited in the extensor digitorum communis (EDC), ECU, and EIP. Volitional contraction of the supinator was not possible due to severe pain; MUAP was not evaluated in the left supinator. Abnormal spontaneous activity was observed in left brachioradialis, ECRL, EDC, ECU, EIP, and supinator. In the left triceps brachii, there was no abnormal spontaneous activity and MUAP was fully recruited. Ultrasonography and magnetic resonance imaging (MRI) of the left elbow demonstrated increased diameter of the radial nerve and PIN. There were no abnormal findings in SRN (Fig. 1). X-ray of the left elbow revealed no bony abnormality.

She underwent a surgical exploration and decompression 10 days after the EMG/NCS. During the operation, it was noted that the left PIN was compressed by the supinator muscle and showed edematous and yellowish color changes. After the operation, the left arm pain was completely relieved. At 6 months after the operation, finger extensors and wrist ulnar dorsiflexor showed slight muscle contraction with evidence of reinnervation in 

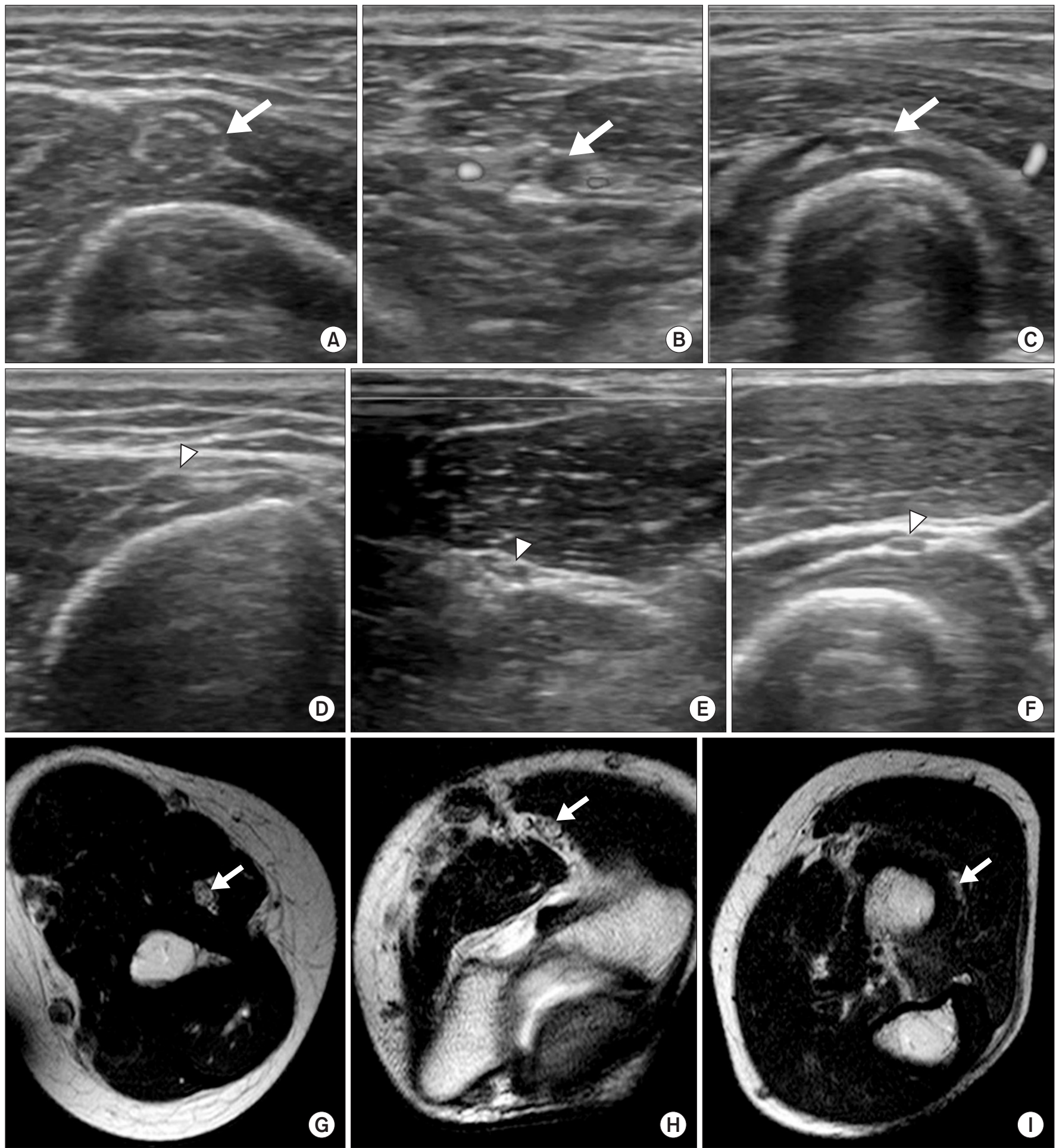

Fig. 1. Transverse ultrasonographic scan findings. The scan was performed at the dorsolateral aspect of the distal upper arm (A, left; D, right), at the bifurcation of the radial nerve (B, left; E, right), and at the proximal supinator (C, left; F, right); and T2-weighted magnetic resonance imaging in the axial section at the mid humerus $(\mathrm{G})$, distal humerus $(\mathrm{H})$, and proximal supinator (I) depicting the radial nerve of the affected (arrow) and unaffected sides (arrow head). Diameter of the radial nerve of the affected side is increased above the proximal portion of the supinator muscle. 
the EDC, ECU, and EIP on EMG. Nine months after the operation, the manual muscle test and EMG findings indicated further improvement (Table 1).

\section{DISCUSSION}

Neurostenalgia is a continuous neuropathic pain associated with nerve palsy. A characteristic feature of neurostenalgia is prompt resolution of pain after surgical release of the nerve in previously [2-7]. We report a case of PIN entrapment with severe pain. Nerve entrapment at the arcade of Frohse was noticed on ultrasonography and MRI, and confirmed upon surgery. EMG/NCS confirmed nerve injury of PIN and radial nerve. The painful disability was immediately resolved after surgical release. The clinical findings were compatible with neurostenalgia. Most patients with PIN entrapment present as weakness of wrist and finger extensors innervated by the PIN, and pain is typically mild discomfort in the forearm $[1,8]$. Severe painful condition associated with weakness can be misdiagnosed as neuralgic amyotrophy. The pain is typically severe in neuralgic amyotrophy; it is commonly worsened by movement of the shoulder or arm, resulting in patients holding the arm with the elbow flexed and the shoulder adducted [9]. Contrary to entrapment neuropathy, treatment of neuralgic amyotrophy is steroid therapy and not surgical release.

Neurostenalgia is a rare condition that has important clinical significance because it causes significantly disabling pain that can promptly resolve after surgical release. All of the six previously reviewed cases of neurostenalgia showed improvement in the pain after surgical release [2-7]. There was a case report of neurostenalgia of the radial nerve occurred after operation of a humeral lengthening frame to the humerus [3]. As far as we know, a neurostenalgia of the radial nerve without preceding noxious event has not reported.

In summary, neurostenalgia of the radial and posterior interosseous nerve is uncommon. Because of severe localized and neuropathic pain, this condition can be mistaken for neuralgic amyotrophy. Pain in neurostenalgia is resolved after surgical release unlike neuralgic amyotrophy. Ultrasonographic and MRI findings suggesting focal entrapment can be a clue to the diagnosis of neurostenalgia. After decompression of the nerve, the patient was immediately pain-free and a gradual neurological recovery followed. We believe that this case serves as a reminder of the importance of a careful and elaborate history taking and clinical examination.

\section{CONFLICT OF INTEREST}

No potential conflict of interest relevant to this article was reported.

\section{REFERENCES}

1. Rosenbaum R. Disputed radial tunnel syndrome. Muscle Nerve 1999;22:960-7.

2. Camp SJ, Milani R, Sinisi M. Intractable neurostenalgia of the ulnar nerve abolished by neurolysis 18 years after injury. J Hand Surg Eur Vol 2008;33:45-6.

3. Halliday J, Hems T, Simpson H. Beware the painful nerve palsy; neurostenalgia, a diagnosis not to be missed. Strategies Trauma Limb Reconstr 2012;7:177-9.

4. Montgomery AS, Birch R, Malone A. Sciatic neurostenalgia: caused by total hip arthroplasty, cured by late neurolysis. J Bone Joint Surg Br 2005;87:410-1.

5. Oschman Z, Koekemoer A. Ultrasound diagnosis of femoral nerve neurostenalgia: a cause of hip pain in a young adult. SA Orthop J 2012;11:36-8.

6. Phang IS, Biant LC, Jones TS. Neurostenalgia of the femoral nerve: a treatable cause of intractable hip pain in a young adult. J Arthroplasty 2010;25:498.e15-7.

7. Simpson CK, Butt AM, Power D. Neurostenalgia as a cause of pain after tendon and nerve repair at the wrist. J Hand Surg Eur Vol 2013;38:687-8.

8. Han TR, Kim JH, Kwon YW. A study for etiologic mechanism of spontaneous posterior interosseous neuropathy. J Korean Acad Rehabil Med 1994;18:518-23.

9. Sathasivam S, Lecky B, Manohar R, Selvan A. Neuralgic amyotrophy. J Bone Joint Surg Br 2008;90:550-3. 